\title{
THE INTERNATIONALIZATION PROCESS OF THE FIRM-A MODEL OF KNOWLEDGE DEVELOPMENT AND INCREASING FOREIGN MARKET COMMITMENTS
}

\author{
JAN JOHANSON* \\ Center of International Business Studies \\ University of Uppsala \\ JAN-ERIK VAHLNE* \\ Institute of International Business \\ Stockholm School of Economics
}

\begin{abstract}
On the basis of empirical research, a model of the internationalization process of the firm is developed. The model focuses on the gradual acquisition, integration and use of knowledge about foreign markets and operations, and on the incrementally increasing commitments to foreign markets. In particular, attention is concentrated on the increasing involvement in the individual foreign country.
\end{abstract}

Several studies of international business have indicated that internationalization of the firms is a process in which the firms gradually increase their international involvement. It seems reasonable to assume that, within the frame of economic and business factors, the characteristics of this process influence the pattern and pace of internationalization of firms. In this paper we develop a model of the internationalization process of the firm that focuses on the development of the individual firm, and particularly on its gradual acquisition, integration, and use of knowledge about foreign markets and operations, and on its successively increasing commitment to foreign markets. The basic assumptions of the model are that lack of such knowledge is an important obstacle to the development of international operations and that the necessary knowledge can be acquired mainly through operations abroad. This holds for the two directions of internationalization we distinguish: increasing involvement of the firm in the individual foreign country, and successive establishment of operations in new countries. In this paper we will, however, concentrate on the extension of operations in individual markets.

We have incorporated in our model some results of previous empirical studies of the development of international operations, seeking theoretical explanation through the behavioral theory of the firm (Cyert and March, 1963). Specifically, we believe that internationalization is the product of a series of incremental decisions. Our aim is to identify elements shared in common by the successive decision situations and to develop thereby a model of the internationalization process which will have explanatory value. Because we, for the time being, disregard the decision style of the decision-maker himself, and, to a certain extent, the specific properties of the various decision situations, our model has only limited predictive value. We believe, however, that all the decisions that, taken together, constitute the internationalization process-decisions to start exporting to a country, to establish export channels, to start a selling subsidiary, and so forth-have some common characteristics which are also very important to the subsequent internationalization. Our model focuses on these common traits.

We hope that the model will contribute to conceptualization in the field of internationalization of the firm and thus increase understanding of the development of international operations as described in the empirical studies. We hope, too, that it can serve as a frame of reference for future studies in the problem area and may also be useful as a tool in the analysis of the effects of various factors on the pattern and pace of internationalization of the firm.

\footnotetext{
* Jan Johanson is a member of the faculty of the Center for International Business Studies at the University of Uppsala, Sweden. Jan-Erik Vahlne is on the faculty of the Institute of International Business, Stockholm School of Economics, Stockholm, Sweden.

The authors are indebted to their colleagues at the Center for Internatonal Business Studies, Department of Business Administraton, University of Uppsala for valuable comments and to David Baker for careful criticism of content and language. Financial support has been given by the Svenska Handelsbanken Foundation for Social Science Research.
} 
In the first section we described the empirical background of our study. Next we outline the model of the internationalization process, defining the main variables and the interaction among them. We then sum up by discussing some implications of the model and suggesting some problems for future research.

EMPIRICAL BACKGROUND
The model is based on empircal observations from our studies in international business at the University of Uppsala, that show that Swedish firms often develop their international operations in small steps, rather than by making large foreign production investments at single points in time. Typically, firms start exporting to a country via an agent, later establish a sales subsidiary, and eventually, in some cases, begin production in the host country.

We have also observed a similar successive establishment of operations in new countries. Of particular interest in the present context is that the time order of such establishments seems to be related to the psychic distance between the home and the import/host countries (Hörnell, Vahlne \& Wiedersheim-Paul, 1972, Johanson \& Wiedersheim-Paul, 1974). The psychic distance is defined as the sum of factors preventing the flow of information from and to the market. Examples are differences in language, education, business practices, culture, and industrial development.

Studies of the export organization of the Swedish special steel firms (Johanson, 1966) and of the Swedish pulp and paper industry (Forsgren \& Kinch, 1970) have shown that almost all sales subsidiaries of Swedish steel companies and pulp and paper companies have been established through acquisition of the former agent or have been organized around some person employed by the agent. Most of the establishments were occasioned by various kinds of economic crises in the agent firms. Sales to a market by the agent had preceded establishment of a sales subsidiary in each of nine cases investigated by Hörnell and Vahlne (1972). Further case studies of the development of international activities by Swedish firms have allowed us to generalize our observations: sales subsidiaries are preceded in virtually all cases by selling via an agent; similarly, local production is generally preceded by sales subsidiaries.

A summary of the results we reached in two studies follows. They are by no means meant to be statistically representative, but the results are typical of studies we know. The first example is a case study of the internationalization process of the second largest Swedish pharmaceutical firm, Pharmacia. At the time of the case study (1972) Pharmacia had organizations of its own in nine countries, of which three were performing manufacturing activities. In eight of these cases the development pattern was as follows. The firm received orders from the foreign market and after some time made an agreement with an agent (or sold licenses regarding some parts of the product line). After a few years Pharmacia established sales subsidiaries in seven of those countries (and in the eighth they bought a manufacturing company bearing the same name, Pharmacia, that had previously served as an agent). Two of the seven sales subsidiaries further increased their involvement by starting manufacturing activities. It is interesting to note that even this production decision was incremental; the new production units began with the least complicated manufacturing activities and later successively added more complicated ones.

In the ninth country Pharmacia started a sales subsidiary almost immediately when demand from the market was discovered. But the company did not totally lack experience even in this case. The decision-maker had received parts of his education in the country in question, and before the decision he had become acquainted with the representative of another pharmaceutical firm who was later made the head of the subsidiary (Hörnell, Vahlne, \& Wiedersheim-Paul, 1973).

In another study we investigated the internationalization of four Swedish engineering firms. Below we quote some of the conclusions of the study (Johanson \& Wiedersheim-Paul, 1975).

The establishment chain-no regular export, independent representative (agent), sales subsidiary, production-seems to be a correct description of the order of the development operations of the firms in individual countries. This is illustrated in Table I. Of sixty-three sales subsidiaries fifty-six were preceded by agents; this pattern holds for all the firms. With regard to the production establishments there is a difference between Sandvik and Atlas Copco on 
Table I

Establishment Patterns for the Investigated Firms.

\begin{tabular}{|c|c|c|c|c|c|c|}
\hline \multirow[b]{2}{*}{ Firm } & \multirow{2}{*}{ Pattern } & \multicolumn{2}{|c|}{$\begin{array}{c}\text { Sales } \\
\text { subsidiary }\end{array}$} & & \multicolumn{2}{|c|}{$\begin{array}{l}\text { Production } \\
\text { subsidiary }\end{array}$} \\
\hline & & $\begin{array}{l}n \\
\downarrow \\
s\end{array}$ & $\begin{array}{l}a \\
\downarrow \\
s\end{array}$ & $\begin{array}{l}n \\
\downarrow \\
p\end{array}$ & $\begin{array}{l}\mathrm{a} \\
\downarrow \\
\mathrm{p}\end{array}$ & $\begin{array}{l}s \\
\downarrow \\
p\end{array}$ \\
\hline Sandvik & & 2 & 18 & 0 & 2 & 13 \\
\hline Atlas Copco & & 3 & 14 & 0 & 3 & 9 \\
\hline Facit & & 0 & 14 & 0 & 2 & 3 \\
\hline Volvo & & 2 & 10 & 0 & 2 & 3 \\
\hline & & 7 & 56 & 0 & 9 & 28 \\
\hline
\end{tabular}

" $n$ " denotes no regular export activity

"a" denotes selling via agent

"s" denotes sales subsidiary

"p" denotes production subsidiary

an arrow denotes change from one state to another

one hand, where twenty-two out of twenty-seven establishments were preceded by sales subsidiaries, and Facit and Volvo on the other, where five out of seven occurred without the firm having any sales subsidiary in the country. However, in no case has a firm started production in a country without having sold in the country via an agency or a sales subsidiary before

Regarding the first establishments of sales subsidiaries, they do not seem to have been a step in a conscious and goal directed internationalization-at least not in Sandvik, Atlas Copco, and Volvo. For various reasons they had to take over representatives or start subsidiaries. As they gradually have gained experience in starting and managing subsidiaries, they have developed policies of marketing through subsidiaries in some of the firms. It should be noted that the firm, Atlas Copco, which most consistently used subsidiaries for export marketing did so when it acquired a new general manager, a former manager of a department store.

The producing subsidiaries almost all produce for local or in some cases regional markets. Their activity embraces finishing, assembly, or component works which could be called marketing production. The only exception is Atlas Copco's factory in Belgium making stationary pneumatic equipment.

Generally the development of the firm seems to be in accordance with the incremental internationalization view discussed.

This gradual internationalization is not exclusively a Swedish phenomenon, as the following quotations demonstrate:

On its part exporting is a means also of reducing costs of market development. Even if investment is necessary in the future, exporting helps to determine the nature and size of the market. As the market develops, warehouse facilities are established: later sales branches and subsidiaries (Singer, National Cash Register, United Show Machinery). The record of company development indicates that the use of selling subsidiaries at an early stage reduced the later risks of manufacturing abroad. These selling affiliates permitted the slow development of manufacturing from repairing, to packaging, to mixing, to finishing, to processing or assembling operations, and finally to full manufacture (Behrman, 1969, p 3).

Within countries there is often a pattern of exports from the United States, followed by the establishment of an assembly or packaging plant, followed by progressively more integrated manufacturing activities (Vaupel, 1971, p 42).

Without reference to any specific empirical observations Gruber, Mehta, and Vernon (1967) mention that "one way of looking at the overseas direct investments of U.S. producers of manufacturers is that they are the final step in a process which begins with the involvement of such producers in export trade". Knickerbocker (1972) also refers to this process and explicitly distinguishes agents and sales subsidiaries as separate steps in the process. Lipsey and Weiss (1969; 1972) refer to a "market cycle" model with similar characteristics. However, in none of these cases have the dynamics of this process been investigated. It has only been used as an argument in the discussion of related problems 
Specificaton of the Problem
If internationalization indeed follows the pattern described above, how can we explain it? We do not believe that it is the result of a strategy for optimum allocation of resources to different countries where alternative ways of exploiting foreign markets are compared and evaluated. We see it rather as the consequence of a process of incremental adjustments to changing conditions of the firm and its environment (cf. Aharoni, 1966).

Changes in the firm and its environment expose new problems and opportunities. Lacking routines for the solution of such sporadic problems, the concern's management "searches in the area of the problem" (Cyert and March, 1963). Each new discontinuity is regarded as an essentially unprecedented and unparalleled case; the problems and opportunities presented are handled in their contexts. Thus commitments to other markets are not explicitly taken into consideration; resource allocations do not compete with each other.

Another constraint on the problem solution is the lack of, and difficulty of obtaining market knowledge in international operations. That internationalization decisions have an incremental character is, we feel, largely due to this lack of market information and the uncertainty occasioned thereby (Hörnell, Vahlne and Wiedersheim-Paul, 1972; Johanson, 1970). We believe that lack of knowledge due to differences between countries with regard to, for example, language and culture, is an important obstacle to decision making connected with the development of international operations. We would even say that these differences constitute the main characteristic of international, as distinct from domestic, operations. By market knowledge we mean information about markets, and operations in those markets, which is somehow stored and reasonably retrievable -in the mind of individuals, in computer memories, and in written reports. In our mode we consider knowledge to be vested in the decision-making system: we do not deal explicitly with the individual decision-maker.

THE INTERNATIONALIZATION MODEL

As indicated in the introduction, a model in which the same basic mechanism can be used to explain all steps in the internationalization would be useful. We also think that a dynamic model would be suitable. In such a model the outcome of one decision-or more generally one cycle of events-constitutes the input of the next. The main structure is given by the distinction between the state and change aspects of internationalization variables. To clarify, we can say that the present state of internationalization is one important factor explaining the course of following internationalization, as in expression (1) below.

$\Delta \mathrm{l}=\mathrm{f}(\mathrm{l}$. . . )

where

1 = state of internationalization

The state aspects we consider are the resource commitment to the foreign markets-market commitment-and knowledge about foreign markets and operations. The change aspects are decisions to commit resources and the performance of current business activities. The basic mechanism is illustrated schematically in Figure 1.

Figure 1. The Basic Mechanism of Internationalization-State and Change Aspects.

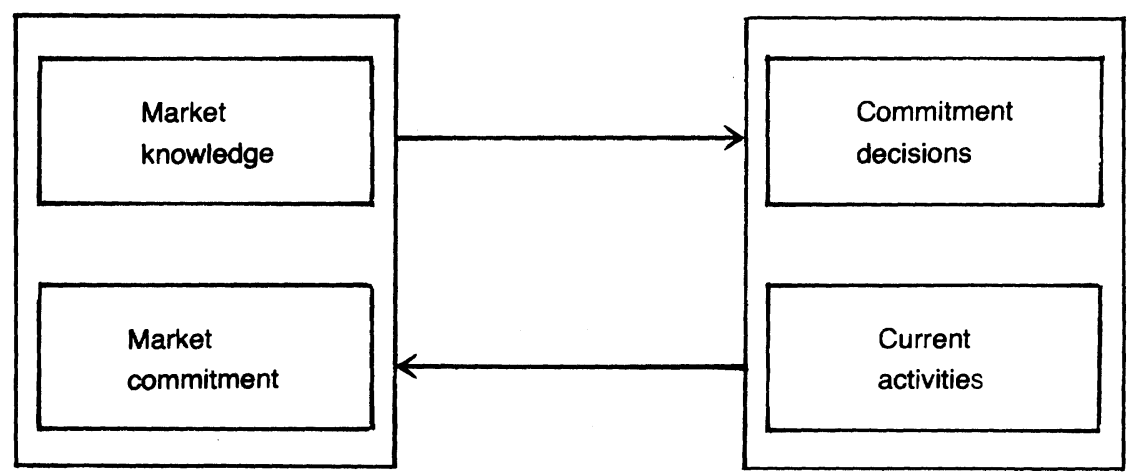


Market knowledge and market commitment are assumed to affect both commitment decisions and the way current activities are performed. These in turn change knowledge and commitment (cf. Aharoni, 1966).

In the model, it is assumed that the firm strives to increase its long-term profit, which is assumed to be equivalent to growth (Williamson, 1966). The firm is also striving to keep risk-taking at a low level. These strivings are assumed to characterize decision-making on all levels of the firm. Given these premises and the state of the economic and business factors which constitute the frame in which a decision is taken, the model assumes that the state of internationalization affects perceived opportunities and risks which in turn influence commitment decisions and current activities. We will discuss the mechanism in detail in the following sections.

The two state aspects are resources committed to foreign markets-market commitment-and knowledge about foreign markets possessed by the firm at a given point of time. The reason for considering the market commitment is that we assume that the commitment to a market affects the firm's perceived opportunities and risk.

Let us first take a look at the market commitment concept. To begin with, we assume that it is composed of two factors - the amount of resources committed and the degree of commitment, that is, the difficulty of finding an alternative use for the resources and transferring them to it. Resources located in a particular market area can often be considered a commitment to that market. However, in some cases such resources can be sold and the financial resources can easily be used for other purposes. The degree of commitment is higher the more the resources in question are integrated with other parts of the firm and their value is derived from these integrated activities. Thus, as a rule, vertical integration means a higher degree of commitment than a conglomerative foreign investment. An example of resources that cannot easily be directed to another market or used for other purposes is a marketing organization that is specialized around the products of the firm and has established integrated customer relations. However, resources located in the home country and employed in development and production of products for a separate market also constitute a commitment to that market. The more specialized the resources are to the specific market the greater is the degree of commitment. And even if such resources can easily be directed to development and production for other markets, as for example engineers in a central engineering department, they cannot always be profitably used there. Consider Volvo-the Swedish car manufacturer-with a large part of its production capacity employed in production of cars for the U.S. market. Even if that capacity is not highly committed to the U.S. production, it is not easy, at least in the short run, to use it for production for other markets. And although the engineers employed in adapting the car to the U.S. requirements can probably be used for another purpose, it is not certain that they can be profitably employed there. On the whole, it seems reasonable to assume that the resources that are located in the particular market are most committed to that market; but we shall not disregard the commitment that follows from employing parts of the domestic capacity for a particular market.

The other part of market commitment-the amount of resources committed-is easy to grasp. It is close to the size of the investment in the market, using this concept in a broad sense, including investment in marketing, organization, personnel, and other areas.

In our model, knowledge is of interest because commitment decisions are based on several kinds of knowledge. First, knowledge of opportunities or problems is assumed to initiate decisions. Second, evaluation of alternatives is based on some knowledge about relevant parts of the market environment and about performance of various activities. Very generally, the knowledge "relates to present and future demand and supply, to competition and to channels for distribution, to payment conditions and the transferability of money, and those things vary from country to country and from time to time"'(Carlson, 1974).

\section{State Aspects}

\section{Market Commitment}

\section{Market Knowledge}


A classification of knowledge which is useful for us is based on the way in which knowledge is acquired (Penrose, 1966, p 53). "One type, objective knowledge, can be taught; the other, experience or experiential knowledge, can only be learned through personal experience. With experiential knowledge, emphasis is placed on the change in the services the human resources can supply which arises from their activity" (ibid, p 53); and ". . . experience itself can never be transmitted, it produces a change-frequently a subtle change-in individuals and cannot be separated from them" (ibid, p 53). "Much of the experience of businessmen is frequently so closely associated with a particular set of circumstances that a large part of a man's most valuable services may be available only under these circumstances" (ibid, p 53).

We believe that this experiential knowledge is the critical kind of knowledge in the present context. It is critical because it cannot be so easily acquired as objective knowledge. In domestic operations, we can to a large extent rely on lifelong basic experiences to which we can add the specific experiences of individuals, organizations and markets. In foreign operations, however, we have no such basic experiential knowledge to start with. It must be gained successively during the operations in the country.

We believe that the less structured and well defined the activities and the required knowledge are, the more important is experiential knowledge. We think that it is particularly important in connection with activities that are based on relations to other individuals. Managerial work and marketing are examples of such activities. Especially in the marketing of complex and soft-ware-intensive products, experiential knowledge is crucial.

An important aspect of experiential knowledge is that it provides the framework for perceiving and formulating opportunities. On the basis of objective market knowledge it is possible to formulate only theoretical opportunities; experiential knowledge makes it possible to perceive "concrete" opportunities-to have a "feeling" about how they fit into the present and future activities.

We can also distinguish between general knowledge and market-specific knowledge. General knowledge concerns, in the present context, marketing methods and common characteristics of certain types of customers, irrespective of their geographical location, depending, for example, in the case of industrial customers, on similarities in the production process. The market-specific knowledge is knowledge about characteristics of the specific national market-its business climate, cultural patterns, structure of the market system, and, most importantly, characteristics of the individual customer firms and their personnel.

Establishment and performance of a certain kind of operation or activity in a country require both general knowledge and market-specific knowledge. Market-specific knowledge can be gained mainly through experience in the market, whereas knowledge of the operation can often be transferred from one country to another country. It is the diffusion of this general knowledge which facilitates lateral growth; that is, the establishment of technically similar activities in dissimilar business environments.

There is a direct relation between market knowledge and market commitment. Knowledge can be considered a resource (or, perhaps preferably, a dimension of the human resources), and consequently the better the knowledge about a market, the more valuable are the resources and the stronger is the commitment to the market. This is especially true of experiential knowledge, which is usually associated with the particular conditions on the market in question and thus cannot be transferred to other individuals or other markets.

The change aspects we have considered are current activities and decisions to commit resources to foreign operations.

Current Business Activities
There is, to begin with, a lag between most current activities and their consequences. Those consequences may, in fact, not be realized unless the activities are repeated more or less continuously. Consider, for example, marketing activities, which generally do not result in sales unless they are repeated for some time. In many cases the time lag is considerable, and the marketing investment represents an important and ever-increasing commitment to the market. The longer the lag, the higher the commitment of the firm mounts. It seems reasonable to assume that the more complicated and the more differentiated the product is, the larger the total commitment as a consequence of current activities will come to be. 
Current activities are also the prime source of experience. It could be argued that experience could be gained alternatively through the hiring of personnel with experience, or through advice from persons with experience. To clarify the roles of these alternative ways of integrating experience into the firm in the internationalization process, we distinguish between firm experience and market experience, both of which are essential. Persons working on the boundary between the firm and its market must be able to interpret information from inside the firm and from the market. The interpretation of one kind of information is possible only for one who has experience with the other part. We conclude that, for the performance of marketing activities, both kinds of experience are required; and in this area it is difficult to substitute personnel or advice from outside for current activities. The more the activities are production-oriented, or the less interaction is required between the firm and its market environment, the easier it will be to substitute hired personnel or advice for current activities; and consequently the easier it will be to start new operations that are not incremental additions to the former operations. It should be remembered, however, that even production activities are dependent on the general business climate, which cannot easily be assessed in ways other than performance of business activities.

To some extent it may be possible to hire personnel with market experience and to use them profitably after some time in the marketing activities. The delay is occasioned by the need for the new personnel to gain the necessary experience in the firm. But if the new personnel have already worked as representatives for the exporter, the delay may approach zero. Thus, the best way to quickly obtain and use market experience is to hire a sales manager or a salesman of a representative or to buy the whole or a part of the firm. In many cases this kind of experience is not for sale; at the time of entry to a market the experience may not even exist. It has to be acquired through a long learning process in connection with current activities. This factor is an important reason why the internationalization process often proceeds slowly.

The second change aspect is decisions to commit resources to foreign operations. We assume that such decisions depend on what decision alternatives are raised and how they are chosen. Regarding the first part we assume that decisions are made in response to perceived problems and/or opportunities on the market. Problems and opportunities-that is awareness of need and possibilities for business actions-are assumed to be dependent on experience. Like Penrose, we might even say that opportunities_and problems-are part of that experience. Firm experience, as well as market experience, is relevant. Problems are mainly discovered by those parts of the organization that are responsible for operations on the market and primarily by those who are working there. For them, the natural solution to problems will be the extension of the operations on the market to complementing operations. In any case we assume that solutions to market operations problems are searched for in the neighborhood of the problem symptoms, that is in the market activities (Cyert \& March, 1963). In the same way opportunities will be perceived mainly by those who are working on the market, and such opportunities will also lead to extension of the operations on the market. They will be related to those parts of the environment that the firm is interacting with (Pfeffer, 1974). Thus, whether decision alternatives are raised in response to problems or in response to opportunities, they will be related to the operations currently performed on the market. Alternative solutions will generally consist of activities that mean an extension of the boundaries of the organization and an increase in commitment to the market. We could speak of an opportunity horizon that-given the operations performed-describes the kind of activities that are likely to be suggested by those responsible for operations.

But opportunities are also seen by individuals in organizations with which the firm is interacting; these individuals may propose alternative solutions to the firm in the form of offers or demands. The probability that the firm is offered opportunities from outside is dependent on the scale and type of operations it is performing; that is, on its commitment to the market.

We distinguish between an economic effect and an uncertainty effect of each additional commitment. We assume that the economic effect is associated primarily with increases in the scale of operations on the market, and that the uncertainty effect concerns the market uncertainty, that is the decision-makers' perceived lack of ability to estimate the present and future market and market-influencing factors. We mean that this market uncertainty is reduced through increases in interaction and integration with the market environment-steps such as increases in communication with customers, establishment of new service activities or, in the extreme case, the take-over of customers.

Commitment Decisions 
Our thinking on this point is further illustrated by the system of relationships below:

$$
\begin{aligned}
& R_{i}^{*}= \text { maximum tolerable market (market } i \text { ) risk }=f \text { (firm's resource position, firm's risk } \\
& \text { approach) } \\
& R_{i}= \text { existing market risk situation }=C_{i} \cdot U_{i} \\
& \text { where } C_{i}=\text { existing market commitment } \\
& \quad U_{i}=\text { existing market uncertainty }
\end{aligned}
$$

$\Delta R_{i}=$ incremental risk implied by an incremental addition to operations on market $\mathrm{i}$.

Scale increasing decisions are assumed to affect the size of $C_{i}$ but not the size of $U_{i}$ so that

$\triangle R_{i}=U_{i} \cdot \Delta C_{i}>0$

Uncertainty reducing decisions are assumed to affect $U_{i}$ primarily so that

$\Delta R_{i}=\Delta U_{i}\left(C_{i}+\Delta C_{i}\right)+\Delta C_{i} \cdot U_{i}<0$

Using this framework we say that scale-increasing decisions will be taken when $R_{i}<R^{\star}$. The firm will incrementally extend its scale of existing operations on the market-in expectation of large returns-until its tolerable risk frontier $\left(R_{i}^{*}\right)$ is met. Scale-increasing commitments may, for example, be occasioned by a decline in uncertainty about the market $\left(U_{i}\right)$ incidental to gaining market knowledge acquired with experience. Such a decline in market uncertainty can be expected when the market conditions are fairly stable and heterogeneous. If market conditions are very unstable, experience cannot be expected to lead to decreased uncertainty. And, if market conditions are very homogeneous, experience is probably not a necessary requirement for market knowledge. Under such market conditions an optimal scale of operations can be chosen from the beginning. Market uncertainty can also decline as a consequence of a competitive-or political-stabilization of market conditions. Scale-increasing commitments may also follow a rise of the maximum tolerable risk level due to an increase in the total resources of the firm or a more aggressive approach toward risk. We can, in any event, say that large increases in the scale of operations in the market will only take place in firms with large total resources or in firms which feel little uncertainty about the market.

Uncertainty-reducing commitments on the other hand will be made when $R_{i}>R^{\star}$. The firm will respond to this imbalance by taking steps to increase interactions and integration with the market environment. Such an imbalance may be the result of a decrease in the maximum tolerable market risk $\left(R_{i}^{\star}\right)$ or an increase in the existing risk situation on the market $\left.R_{i}\right)$. The latter case may, in its turn, be occasioned by an increase in market commitment $\left(C_{i}\right)$ or market uncertainty $\left(U_{i}\right)$. Market commitments that increase risk are, according to our assumptions, those that increase the scale of existing operations on the market. Such increases are likely to be associated with current activities in an expanding market but can also be a consequence of the scale-increasing decisions discussed in the previous paragraph. Note that increases in the scale of operations on the market can be expected to lead to uncertainty-reducing commitments, that is increased interaction and integration with the market environment. Market uncertainty $\left(\cup_{i}\right)$ can be expected to rise as a consequence of experience in a dynamic market environment, showing that the original perception of the market was too simple. It may also rise because of a structural change in market conditions, for example, in connection with the entrance of new competitors on the market or introduction of new techniques. A typical example of the former is the change of the market situation of Swedish pulp and paper firms due to the entrance of North American producers on the European market (Kinch, 1974). However, increases in market uncertainty due to political changes cannot be expected to lead to the uncertainty-reducing commitments discussed here since such commitments cannot be expected to affect the political situaton.

This discussion requires some further comments. First, it is very partial since we do not take into account how various factors other than scale may affect the economy of the market operations. The technology of the firm probably has a great impact on the economy of different types of market operations. Secondly, the variable "firm's approach to market risk" is a very complicated factor. We can, for example, distinguish between three different strategies with respect to this factor. One may be that a high risk level on one market is compensated by a low risk level on other markets. Another is that the tolerable risk level is the same on all markets. A third is that risk taking on the market is delegated to those working on the market as long as decisions do not require additional resources from the firm.

We conclude this discussion of commitment decisions by observing that additional commitments will be made in small steps unless the firm has very large resources and/or market conditions are stable and homogeneous, or the firm has much experience from other markets with similar 
conditions. If not, market experience will lead to a step-wise increase in the scale of the operations and of the integration with the market environment where steps will be taken to correct imbalance with respect to the risk situation on the market. Market growth will speed up this process.

We think that the general characteristics of the model fit nicely with empirical observations given earlier. In order to validate it empirically we intend to make two kinds of empirical studies. Firstly, we shall make one or two intensive case studies to see if the mechanism can be used for explanation in empirical situations. In those case studies, we shall try to measure the internationalization variables, market commitment and market knowledge, and investigate how they develop during the internationalization of the firm.

Secondly, we intend to make comparative studies of the internationalization courses of different firms. Assuming that such factors as firm size, technology, product line, home country, etc., via the mechanism discussed affect the character of the internationalization in different ways, we will investigate whether firms that differ with respect to those factors also differ with respect to the patterns of internationalization. Such studies will require more systematic discussions of the expected influence of the factors. The present model will constitute the framework of such discussions.

In many countries various programs to affect foreign trade and operations are designed and carried out. Still more are discussed. Usually such programs are based on models in which prices of factors and products in different countries are the only explaining factors. We think that our model can help in giving such discussions and programs a better base. An evaluation of a Swedish export stimulation program showed that the "export stimulation measures affect firms' export behavior in different ways due to differences in their degrees of previous export experience" (Olson, 1975). Our model indicates how such experience can be expected to affect the export behavior. It also makes it possible to develop a better understanding of foreign investment behavior.

We also think that the model can be useful in planning and decision making in the firm with regard to international operations. Many firms consider internationalization a promising strategy. There are, however, numerous examples of firms which have started international operations without success. We think that the importance of the experience factor is often overlooked. The model indicates how it is related to other internationalization variables thus giving a better base for planning and executing the internationalization process.

And finally we hope, as do other students in the field, that our way of reasoning will add something to the understanding of the process by which firms become international or even multinational. Thus, many studies of international trade and investment have shown that oligopolistic industries have the greatest international engagement. Such features as high R\&D intensity, advertising intensity, and efforts at product differentiation characterized these industries (Gruber, Mehta, Vernon, 1967; Hymer, 1960; Kindleberger, 1969; Caves, 1971; Vaupel, 1971). Oligopolistic competition, however, lacks explanatory value at the firm level; we have to look for other features to explain variations in the level of international involvement among the several firms in a given oligopolistic industry (Horst, 1972; Knickerbocker, 1973). Perhaps our model of the internationalization process can help in providing a part of this explanation by stressing the importance of some factors affecting the decision-making process.

Aharoni, Y. The Foreign Investment Decision Process. Boston, 1966.

Behrman, J. Some Patterns in the Rise of the Multinational Enterprise. Chapel Hill, 1969.

Carlson, S. Investment in Knowledge and the Cost of Information. Acta Academiae Regiae Scientiarum Upsaliensis: Uppsala, 1974.

Caves, R.E. "International Corporations: The Industrial Economics of Foreign Investment." Economics (1971): vol. 38.

Cyert, R.M. \& March, J.G. A Behavioral Theory of the Firm. Englewood Cliffs, 1963.

\section{Empirical Verification}

Possible Applications

\section{BIBLIOGRAPHY}


Forsgren, M. \& Kinch, N. Företagets anpassning till förändringar i omgivande system. En studie av massa-och pappersindustrin: Uppsala, 1970.

Gruber, W., Mehta, R., \& Vernon, R. "The R \& D Factor in International Trade and International Investment of the United States." Journal of Political Economy, February 1967.

Horst, T. O. "Firm and Industry Determinants of the Decision to Invest Abroad: An Empirical Study." Review of Economics and Statistics, 1972.

Hymer, S. "The International Operations of National Firms: A Study of Direct Investment," Doctoral dissertation, Mass. Institute of Technology, 1960.

Haåkansson, F. \& Wootz, B. "Supplier Selection in an International Environment-An Experimental Study," Journal of Marketing Research, February 1975.

Hörnell, E., Vahlne, J-E., \& Wiedersheim-Paul F. Export och utlandsetableringar. Stockholm, 1973. Johanson, J., ed., Exportstrategiska problem. Stockholm, 1972.

Johanson, J. "Svenskt kvalitetsstål på utländska marknader," Mimeographed licentiate dissertation, Dept. of Business Administration: Uppsala, 1966.

Johanson, J. \& Wiedersheim-Paul, F. "The Internationalization of the Firm — Four Swedish Cases." Journal of Management Studies, 1975.

Kinch, N. "Utlandsetableringar inom massa-och pappers-industrin." In Företagsekonomisk forskning kring internationellt företagande, edited by Jan-Erik Vahlne. Stockholm, 1974.

Kindleberger, C.P. American Business Abroad. New Haven, 1969.

Knickerbocker, F.T. Oligopolistic Reaction and Multinational Enterprise. Boston, 1973.

Lipsey, R. E. \& Weiss, M.Y. "The Relation of US Manufacturing Abroad to US Exports. A Framework for Analysis." Business and Economics Section Proceedings, American Statistical Association, 1969.

Lipsey, R.E. \& Weiss, M.Y. "Analyzing Direct Investment and Trade at the Company Level," Business and Economic Section Proceedings, American Statistical Association, 1972.

Olson, H. C. Studies in Export Promotion. Attempts to Evaluate Export Stimulation Measures for the Swedish Textile and Clothing Industries. Uppsala, 1975.

Penrose, E. The Theory of the Growth of the Firm. Oxford, 1966.

Pfeffer, J. "Merger as a Response to Organizational Interdependence," Administrative Science Quarterly, 6, (1972).

Vaupel, J.V. "Characteristics and Motivations of the US Corporations that Manufacture Abroad." Mimeographed, Boston, 1971.

Williamson, J. "Profit Growth and Sales Maximization." Economica, 33 (1966). 